\title{
Structure and Mechanical Properties of Polyamide 6/ Brazilian Clay Nanocomposites
}

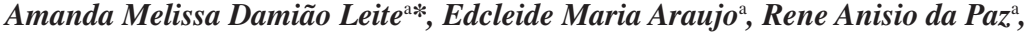 \\ Osanildo Damião Pereira, Hélio Lucena Lira ${ }^{a}$, Edson Noriyuki Ito ${ }^{\mathrm{b}}$ \\ ${ }^{a}$ Federal University of Campina Grande - PB, Brazil \\ ${ }^{\mathrm{b}}$ Federal University of Rio Grande do Norte - RN, Brazil
}

Received: November 5, 2008; Revised: March 16, 2009

\begin{abstract}
Recent interest in polymer/organoclays nanocomposites systems is motivated by the possibility of achieving enhanced properties and added functionality at lower clay loading as compared to conventional micron size fillers. By adding montmorillonite clay to polyamide 6 increases the Young modulus, yield strength and also improves barrier properties. In this work, nanocomposites of polyamide 6 with montmorillonite clay were obtained. The clay was chemically modified with three different quaternary ammonium salts such as: Dodigen, Genamin and Cetremide. In this case, a dispersion of Na-MMT was stirred and a salt equivalent to 1:1 of cation exchange capacity (CEC) of Na-MMT was added to the dispersion. The montmorillonite clay (untreated and treated by ammonium salts) and nanocomposites were characterized by $\mathrm{X}$ ray diffractions. Also the nanocomposites were characterized by transmission electron microscopy and mechanical properties. The results indicated that all the quaternary ammonium salts were intercalated between the layers of clay, leading to an expansion of the interlayer spacing. The obtained nanocomposites showed better mechanical properties when compared to polyamide 6 . The clay acted as reinforcing filler, increasing the rigidity of nanocomposites and decreasing its ductility.
\end{abstract}

Keywords: polyamide 6, Brazilian clay, organoclay, nanocomposites

\section{Introduction}

Polymer clay nanocomposites are a new class of materials that show improved properties at very low concentration of clay compared with conventional filler composites ${ }^{1}$. Polymer composites have been attracted considerable interest as they offer unusual combinations of physical, thermal, mechanical and other properties that are difficult to obtain from pure polymers. Polymer nanocomposites can be differentiated from traditional polymer composites by the size of the filler. Usually, the particle size of the dispersed phase in the nanocomposites should have at least one dimension in nanometer ${ }^{2}$. Because of the nanoscale features of the filler, nanocomposites possess superior properties over their more conventional microcomposites. These properties can be accomplished at very low concentration of clay (a few \%) incorporated in these nanocomposites ${ }^{3,4}$.

The key to such performance is related to the ability of exfoliate and disperse individual particles and the high-aspect ratio silicate platelets within the polymer matrix. Recent studies have explored exfoliated structures from organoclays in a wide range of polymer matrices using different processing routes ${ }^{5}$. To date, well-exfoliated composites have been achieved only with a selected number of polymers, for instance, nylon 6 , polystyrene, polyimide and epoxies ${ }^{6}$. From these, nylon 6 is particularly unique since exfoliated nanocomposites have been formed by more than one processing technique. The technique of melt processing is particularly attractive due to its versatility and compatibility with existing processing used in the industry for commercial applications ${ }^{5}$.

The aim of this work was to obtain polyamide 6 nanocomposites with montmorillonite clay (untreated) and treated with three different quaternary ammonium salts (Dodigen, Genamin and Cetremide) and also to evaluate the structure and mechanical properties of the obtained nanocomposites.

\section{Experimental}

\subsection{Materials}

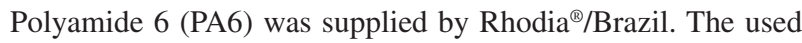
pristine clay was Na-Montmorillonite clay (MMT, Boa Vista/Paraíba, Northeast of Brazil) supplied by Bentonit União Nordeste with a cation exchange capacity (CEC) of 90 meq. $100 \mathrm{~g}^{-1}$ and the interlayer spacing $\left(\mathrm{d}_{001}\right)$ obtained by XRD was $12.74 \AA$ A. MMT was dried at $60^{\circ} \mathrm{C}$ for 48 hours prior to use. The used quaternary ammonium salts for the modification of MMT were: alkyldimethylbenzylammonium chloride (Dodigen), hexadecyltrimethylammonium chloride (Genamin), industrial grades supplied by Clariant/Brazil and hexadecyltrimethylammonium bromide (Cetremide), industrial grade from Vetec/Brazil. These salts were used as received according to the literature ${ }^{7-10}$.

\subsection{Preparation of organoclay}

The preparation of the organophilic montmorillonite with Dodigen and Genamin salts was similar: The Na-MMT was mixed in distilled water with stirring to form a uniformly dispersed suspension. The suspension was stirred for 20 minutes after all the clay has been added. And then, the salt equivalent to 1:1 CEC of Na-MMT was added into the dispersion. The mixture was stirred for more 20 minutes. After 24 hours, the mixture of montmorillonite and the salt were washed with distilled water for several times to remove 
excess salt, dried at $60{ }^{\circ} \mathrm{C}$ for 48 hours, and finally, passed in a sieve 200 mesh. The preparation of the organophilic MMT with Cetremide salt was similar but the mixture in distilled water was heated at $80 \pm 5^{\circ} \mathrm{C}$ and they were kept for 20 minutes with stirring to form a uniformly dispersed suspension. After 24 hours, the same procedure above was made for mixture of montmorillonite and the salt, according to the procedure described by Araújo et al..$^{7-10}$.

\subsection{Nanocomposites preparation}

In the nanocomposite preparation, before any processing step, all the materials containing PA6 were dried in oven were kept in an oven under vacuum at $80^{\circ} \mathrm{C}$ for 24 hours.

The nanocomposites were prepared by two steps. Firstly, in order to assure a better dispersion of the fine clay powder in polyamide, a 1:1 PA6/organoclay master was previously produced in a Torque Rheometer Haake with internal mixer, at $240{ }^{\circ} \mathrm{C}$ and $60 \mathrm{rpm}$ for 10 minutes. After, PA6/organoclay nanocomposites, containing 3 wt. (\%) of clay, were melt in a counter-rotating twin-screw extruder (Torque Rheometer Haake) operating at $240{ }^{\circ} \mathrm{C}$ and $60 \mathrm{rpm}$.

Standard tensile (ASTM D638) and notched Izod impact (ASTM D256) samples were injection moulded in a Fluidmec machine at $240{ }^{\circ} \mathrm{C}$. After moulding, the samples were placed in a desiccator for 48 hours prior to the test.

\subsection{Characterization}

The clays and nanocomposites were characterized by $\mathrm{X}$ ray diffractions (XRD). The measurements were performed at room temperature by a XRD-6000 Shimadzu diffractometer (40 kV, $20 \mathrm{~mA})$ using the $\mathrm{CuK} \alpha$ radiation (wavelength of $0.154 \mathrm{~nm}$ ) at the rate of $2^{\circ}$ per minute, in the range from 2 to $30^{\circ}$. The spacing between the planes was calculated by Braggs's law. TEM was carried out on a Philips ${ }^{\circledR}$ CM120 with an acceleration voltage of $120 \mathrm{kV}$. Samples were cryogenically microtomed into ultrathin sections (25-50 nm thick) from Izod impact bars with a diamond knife using a RMC MT-7000 under cryogenic conditions $\left(-80^{\circ} \mathrm{C}\right)$ inside the microtoming chamber. A cutting speed of $0.1 \mathrm{~mm} / \mathrm{s}$ was maintained throughout the microtoming operation. The ultrathin sections were collected on a copper grid.

Tensile tests were conducted using a LLoyd LR/10KN Universal Machine at room temperature and crosshead speed of $50 \mathrm{~mm} / \mathrm{min}$ for the determination of Young modulus, yield strength measurements, according to the standard ASTM D638. Izod impact tests were carried out on notched specimens at room temperature using a Ceast Resil 5,5 equipment, according to the standard ASTM D256. Typically, five or more samples were used for each determination.

\section{Results and Discussion}

\subsection{X ray diffraction results}

The Figure 1 presents the $\mathrm{X}$ ray patterns of the unmodified clay, organoclay (OMMT), and polyamide 6 nanocomposites. To the unmodified clay, it can be seen the characteristic peak at basal distance of $d_{001}=12.74 \AA$. The interlayer spacing for the treated sample with three quaternary ammonium salts obtained from the corresponding XRD patterns is $23.72 \AA$ (OMMT-Dod), $22.34 \AA$ (OMMT-Gen) and 21.41 $\AA$ (OMMT-Cet), respectively. The interlayer distance was determined by the diffraction peak in the $\mathrm{X}$ ray method, using the Bragg equation. The results indicated that the quaternary ammonium salts were intercalated between the basal planes of clay, leading to an expansion of the interlayer spacing, that is, the treatment with the quaternary ammonium salts was efficient and increase the $\mathrm{d}_{001}$ spacing.
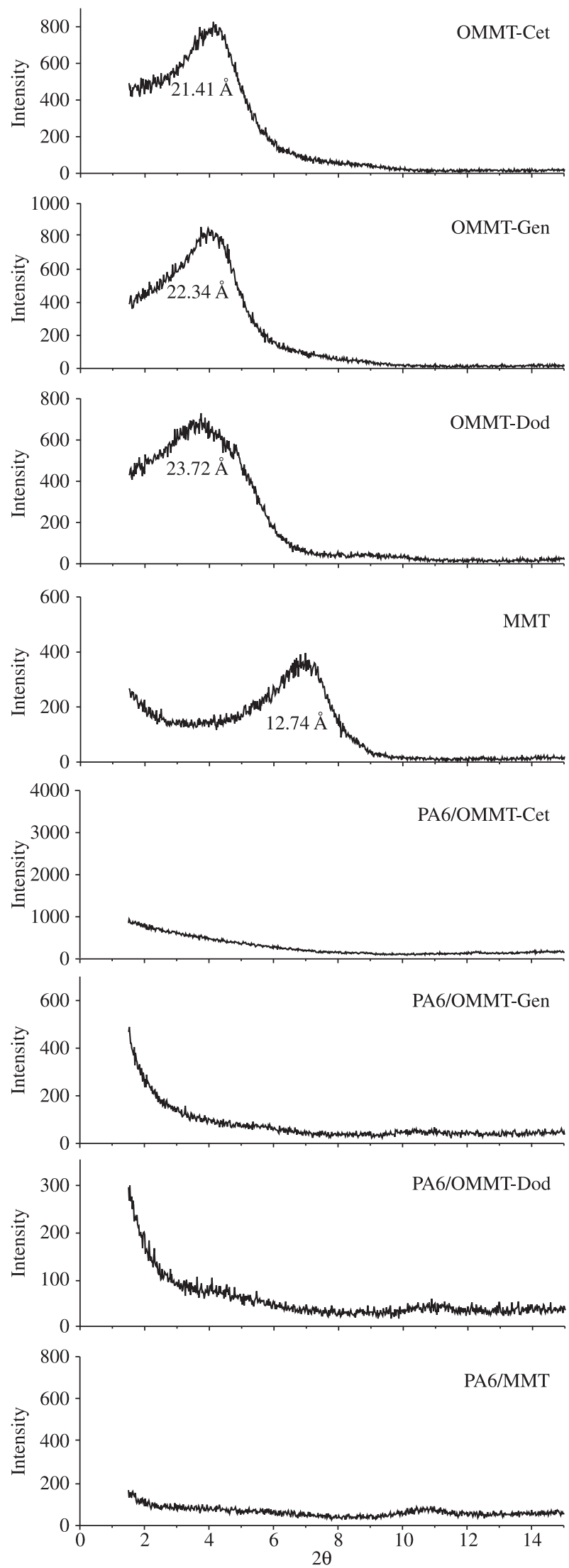

Figure 1. XRD patterns of a) unmodified clay (MMT) and modified with the salts: Dodigen (OMMT-Dod), Genamin (OMMT-Gen), Cetremide (OMMT-Cet); and b) PA6/clay nanocomposites. 
For the nanocomposites, it can be observed the absence of the characteristics peak from clay and this can indicate a nanocomposite with exfoliated structure, according to literature Araújo et al. ${ }^{7-10}$, i.e., apparently, all nanocomposites presented exfoliated structure as reported by Cho and Paul, Sinhá Ray and Okamoto and Paz ${ }^{11-13}$. Theses results are confirmed in this work by TEM analysis.

\subsection{Transmission Electron Microscopy (TEM)}

The Figure 2 shows the obtained photomicrographs by transmission electron microscopy (TEM) for the systems PA6/MMT, PA6/OMMT-Dod, PA6/OMMT-Gen and PA6/OMMT-Cet. In PA6/MMT system, it can be seen clusters but some dispersed layers of clay. However, the PA6 with organoclay systems exhibited exfoliated structure for all the studied salts with some agglomerate. As expected, the presence of the salts in the surface of the clay can change from hydrophilic to hydrophobic characteristic improving the wettability between PA6 and organoclay and promoting the exfoliation of PA6 into interlayers of clay. These results showed the importance of the two techniques (XRD and TEM) to characterize the morphology of the nanocomposites.
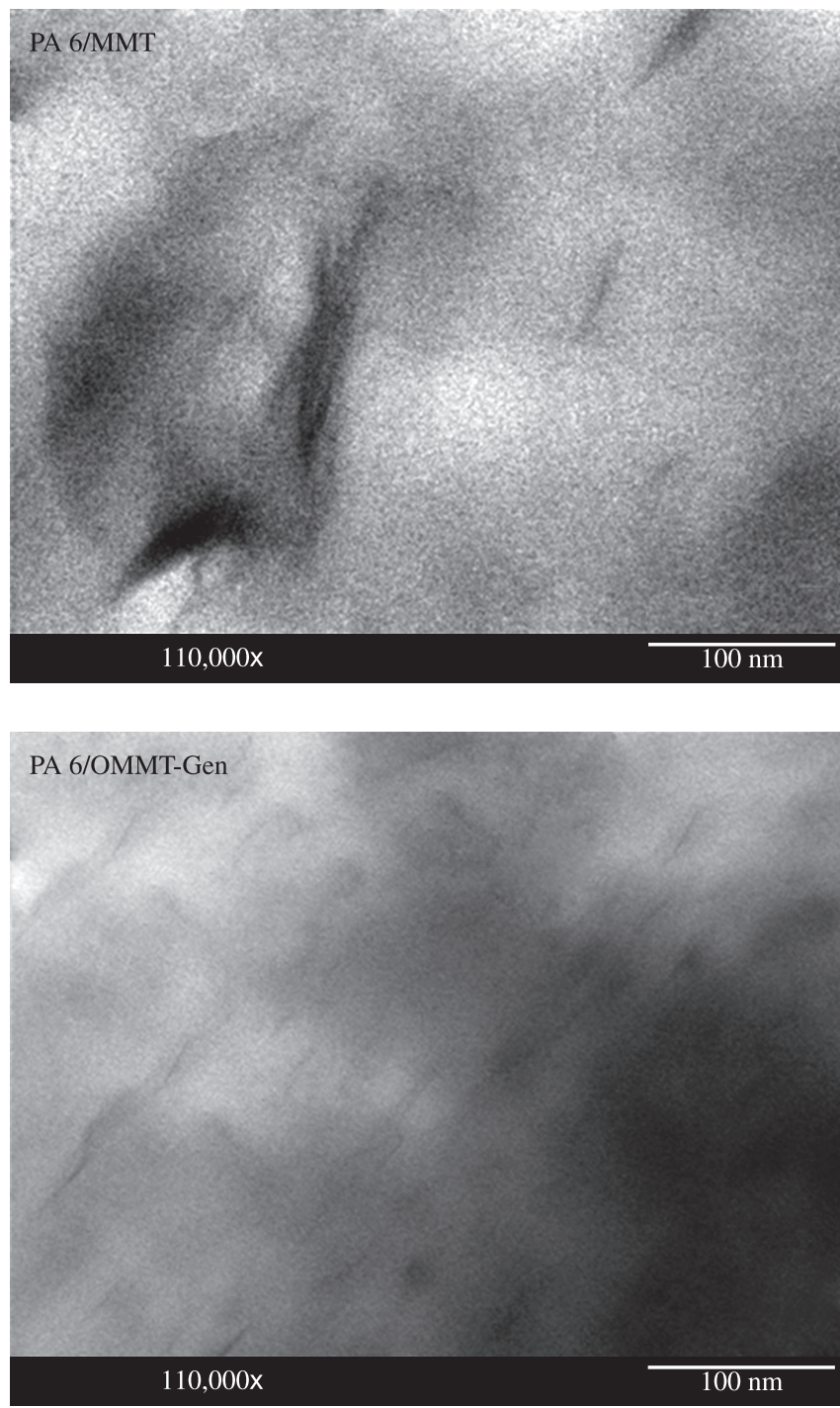

\subsection{Mechanical properties}

Figure 3 shows the mechanical properties of PA6 and its nanocomposites. It can be observed that the nanocomposites exhibit better mechanical properties in relation to pure polyamide 6 , i.e., the nanocomposites present a higher rigidity than the PA6 matrix. Particularly, the PA6/OMMT-Dod system presents higher value for the modulus. This can be attributed to a more exfoliated structure with this salt. Also it can be seen, in the Figure 4, the results of Izod impact strength for the pure PA6 and its nanocomposites. It can be observed that the systems with clay presented impact strength reduced in relation to the matrix. This behavior was expected because the large rigidity of these systems. Probably due, the dispersed layers of clay act as reinforcing agent, reducing the ductility of the system. To the nanocomposites prepared with treated clays, it can be observed the best values of yield strength and Young was obtained by PA6/OMMT-Dod and this behavior is related to a more exfoliated structure as showed in the TEM images (Figure 2).

The results for mechanical properties of pure PA6 and their nanocomposites also revealed that the processing condition used in this

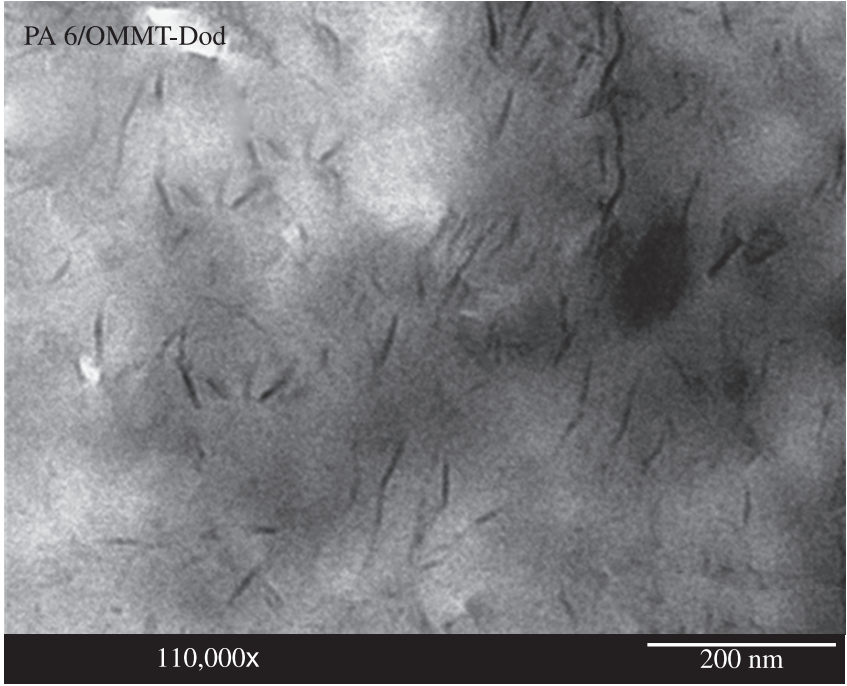

PA 6/OMMT-Cet

Figure 2. TEM photomicrographs of PA6/MMT, PA6/OMMT-Dod, PA6/OMMT-Gen and PA6/OMMT-Cet. 


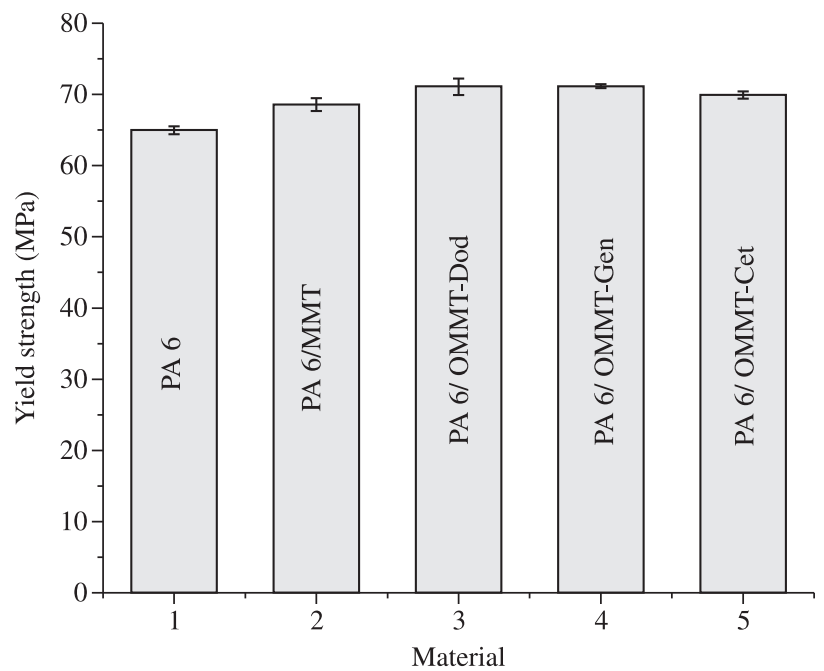

(a)

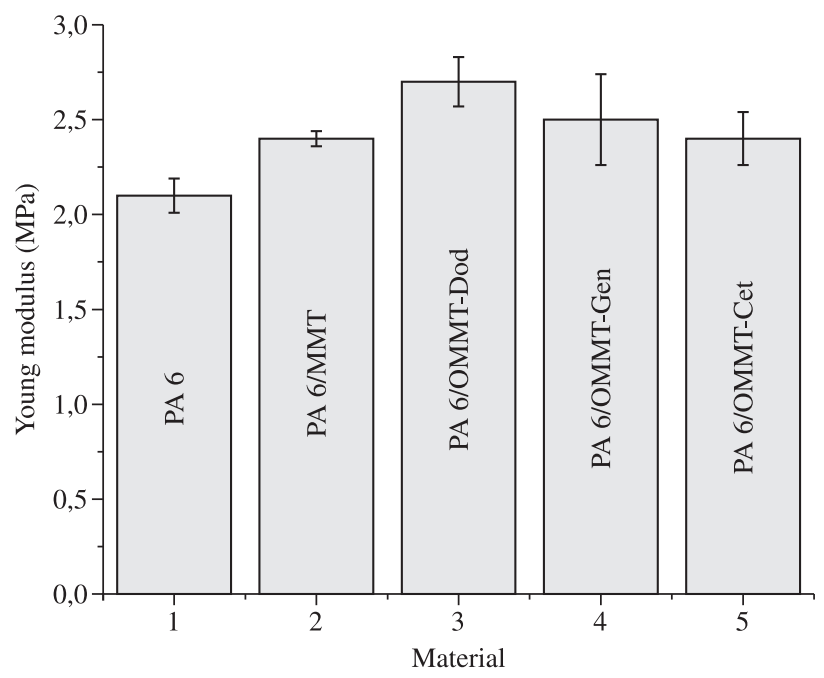

(b)

Figure 3. Mechanical properties of polyamide 6 and its nanocomposites a) yield strength; and b) young modulus.

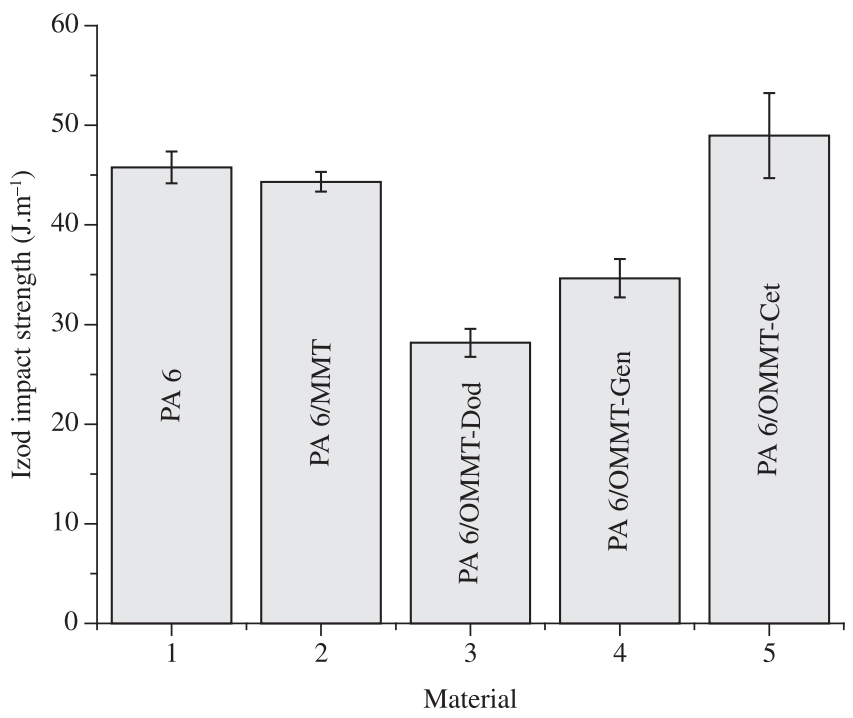

Figure 4. Izod impact strength of PA6 and its nanocomposites. work do not cause a degradation of the polymer and this is confirmed by the previous work done by Araujo et al. ${ }^{10}$ and $\mathrm{Paz}^{13}$.

\section{Conclusions}

The effect of unmodified and modified Brazilian clay with quaternary ammonium salts on the structure and mechanical properties of polyamide 6 nanocomposites was studied in this work. The results indicated the quaternary ammonium salts were intercalated between the basal planes of clay, leading to an expansion of the interlayer spacing. The clay and organoclays presented basal distance of 12.74, 23.72, 22.34 and 21.41 $\AA$ for clay, OMMT-Dod, OMMT-Gen and OMMT-Cet, respectively. The XRD patterns and TEM photomicrographs confirmed that nanocomposites with exfoliated structure were obtained. It was also observed that the nanocomposites exhibited better mechanical properties than pure polyamide 6 . This indicates that PA6/ Brazilian organoclay nanocomposites were obtained with success.

\section{Acknowledgements}

The authors would like to thank to Bentonit União Nordeste, Rhodia, Clariant, RENAMI (Rede de Nanotecnologia Molecular e de Interfaces), CTPETRO/MCT/CNPq, MCT/CNPq/Universal for the financial support.

\section{References}

1. Lopez DG, Mitre IG, Fernandez JF, Merino JC, Pastor JM. Influence of Clay modification process in PA6-layered silicate nanocomposite properties. Polymer. 2005; 46(8):2758-2765.

2. Yu S, Zhao J, Chen G, Juay YK, Yong MS. The characteristics of polyamide layered-silicate nanocomposites. Materials Processing Technology. 2007; 192-193:410-414.

3. Chin IJ, Albrecht TT, Kim HC, Russel T, Wang J. On exfoliation of montmorillonite in epoxy. Polymer. 2001; 42(13):5947-5952.

4. Okamoto M, Morita S, Kotaka T. Dispersed structure and ionic conductivity of smectic clay/polymer nanocomposite. Polymer. 2001; 42(6):2685-2688.

5. Fornes TD, Yoon PJ, Hunter DL, Keskkula H, Paul DR. Effect of organoclay structure on nylon 6 nanocomposite morphology and properties. Polymer. 2002; 43(22):5915-5933.

6. Delozier DM, Orwoll RA, Cahoon JF, Johnston NJ, Smith JG, Connel JW. Preparation and Characterization of polyimide/organoclay nanocomposites. Polymer. 2002; 43(3):813-822.

7. Araújo EM, Barbosa R, Rodrigues AWB, Melo TJA, Ito EN. Processing and characterization of polyethylene/Brazilian Clay nanocomposites. Materials Science and Engineering A. 2007; 445-446:141-147.

8. Araújo EM, Melo TJA, Santana LNL, Neves GA, Ferreira HC, Lira HL. et al. The influence of organo-bentonite clay on the processing and mechanical properties of nylon6 and polystyrene composites. Materials Science and Engineering B. 2004; 112(2-3):175-178.

9. Araújo EM, Barbosa R, Oliveira AD, Morais CRS, Mélo TJA, Souza AG. Thermal and mechanical properties of PE/organoclay nanocomposites. Journal of Thermal Analysis and Calorimetry. 2007; 87(3):811-814.

10. Araújo EM, Barbosa R, Morais CRS, Soledade LEB, Souza AG, Vieira MQ. Effects of organoclays on the thermal processing of pe/clay nanocomposites. Journal of Thermal Analysis and Calorimetry. 2007; 90(3):841-848.

11. Cho J, Paul DR. Polyamide 6 nanocomposites by melt compounding. Polymer. 2001; 42:1083-1094.

12. Ray S, Okamoto M. Polymer/Layered silicate nanocomposites: a review from preparation to processing. Polymer Science. 2003; 28(11):1539-1641.

13. Paz RA. The effect of polyamide 6 (PA6) molecular weight on the development of polymer/layered silicates nanocomposites [Dissertation]. Campina Grande: University of Campina Grande; 2008. 